\title{
The Case for a Critical Zone Science Approach to Research on Estuarine and Coastal Wetlands in the Anthropocene
}

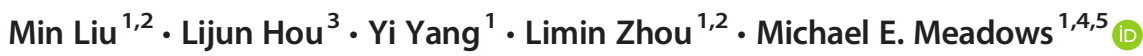 \\ Received: 18 November 2019 / Revised: 1 September 2020 / Accepted: 8 October 2020 / Published online: 15 October 2020 \\ (C) The Author(s) 2020, corrected publication 2020
}

\begin{abstract}
As the focus of land-sea interactions, estuarine and coastal ecosystems perform numerous vital ecological service functions, although they are highly vulnerable to various kinds of disturbance, both directly and indirectly related to human activity, that have attracted much recent attention. Critical zone science (CZS) has emerged as a valuable conceptual framework that focuses on quantitative interactions between diverse components of the environment and is able to integrate anthropogenic disturbance with a view to predicting future trajectories of change. However, coastal and estuarine environments appear to have been overlooked in CZS and are notably under-represented, indeed not explicitly represented at all, in the global network of critical zone observatories (CZOs). Even in the wider network of environmental observatories globally, estuarine and coastal wetland ecosystems are only very rarely an explicit focus. Further strengthening of integrated research in coastal and estuarine environments is required, more especially given the threats these ecosystems face due to growing population at the coast and against the background of climate change and sea level rise. The establishment of one or more CZOs, or their functional equivalents, with a strong focus on estuarine and coastal wetlands, should be urgently attended to.
\end{abstract}

Keywords Coastal environments · Ecosystem services · Human impact · Critical zone observatories $\cdot$ CZO $\cdot$ CZEN $\cdot$ LTER · NEON

Communicated by Kenneth L. Heck

Electronic supplementary material The online version of this article (https://doi.org/10.1007/s12237-020-00851-9) contains supplementary material, which is available to authorized users.

Michael E. Meadows

michael.meadows@uct.ac.za

1 Key Laboratory of Geographic Information Science (Ministry of Education); School of Geographical Sciences, East China Normal University, 500 Dongchuan Road, Shanghai 200241, China

2 Institute of Eco-Chongming, East China Normal University, 500 Dongchuan Road, Shanghai 200241, China

3 State Key Laboratory of Estuarine and Coastal Research, East China Normal University, 3663 North Zhongshan Road, Shanghai 200062, China

4 Department of Environmental and Geographical Science, University of Cape Town, Rondebosch, Cape Town 7701, South Africa

5 College of Geography and Environmental Sciences, Zhejiang Normal University, Jinhua 321004, China

\section{Introduction: The Value of Coastal and Estuarine Wetlands}

Estuarine and coastal regions lie at the nexus of land and ocean and are characterized by a diverse array of coupled geophysical, chemical and biological processes. The complexity of interactions between the various elements and processes has produced a highly sensitive ecological environment, the marked vulnerability of which places a substantial proportion of the global population at risk (Comte et al. 2019). Estuarine and coastal environments are influenced by both terrestrial and marine interactions, for example, alternating influences of saline and fresh water, exposure and inundation and erosion and deposition. The diverse physical, chemical and biological conditions are determined by hydrodynamic processes, including wave action, tidal flows, frequent sediment transport and exchange, steep gradients in physical and chemical factors and a rich and diversified biota etc. (Osland et al. 2013). Lying at the boundary between the land and the ocean, the estuarine and coastal zone is the permeable nearsurface layer from above the coastal vegetation canopy, inclusive of developed and natural tidal affected coastal 
environments, to deep bedrock where meteoric groundwaters have influence. This is a 'critical zone' with unique ecological value and resource potential that provides a wide range of ecological, physical environmental and economic service functions (Barbier et al. 2011; Barbier 2015) but is increasingly impacted by human activities so that the relationship between people and environment has deteriorated rapidly in the recent past, especially in coastal wetlands (Kirwan and Megonigal 2013). There is, therefore, an increasing need for the wider significance of these environments to be recognized and valued so that they can continue to perform their key functions.

Numerous ecosystem benefits emanate from estuarine and coastal wetlands, including the provisioning, regulating, supporting and cultural services. Particular examples include the provision of fisheries, life support services such as nutrient cycling and water purification, physical services including protection from storm surges, as well as education, recreation and even aesthetic benefits. Highlighting the value of such services is challenging, and as Xu et al. (2020) note, there remains a lack of both unified indicators for the assessment of ecosystem services in wetlands as well as a paucity of comprehensive studies. Indeed, coastal and estuarine habitats are a focus in less than $15 \%$ of all ecosystem services publications on wetlands (Xu et al. 2020). On this basis, it would seem that these vulnerable systems are undervalued in relation to the range of services that they provide, although Barbier (2019) notes that economic valuations of ecosystem services in relation to coastal wetlands are increasing in both frequency and accuracy. Estimating the economic value of the diverse range of benefits is regarded as an important key to influencing the approach to policy decisions around conservation and development and, ultimately, to the sustainability of coastal and estuarine wetlands. Figure 1 summarizes why the economic valuation of ecosystem services is important to guide future management decisions as suggested by Sutton-Grier and Sandifer (2019) and Schoutens et al. (2019) who highlight the way in which wetlands can be part of 'nature-based' solutions to environmental hazards such as storms and floods. Their role in coastal protection is perhaps one of the most commonly recognized ecosystem services, and there are many recent studies that emphasize this. For example, Ouyang et al. (2018) describe the pivotal role that coastal wetlands play in mitigating the impacts of cyclones and hurricanes, more especially in the context of climate change, and estimate that the economic value of this approaches US $\$ 200$ billion in China alone. Rezale et al. (2020) demonstrate, for coastal wetlands in New Jersey, USA, that the appropriate management and maintenance of salt marsh vegetation can reduce flooding depths in storm events and significantly reduce property damage in the future, a conclusion also reached by, among others, Highfield et al. (2018), Vásquez-González et al. (2019) and Montgomery et al. (2019). Yang et al. (2018b) document the substantial trade-offs that must be accounted for when these systems are allowed to deteriorate and that coastal land reclamation - a process that has been rampant in Asia in general and in China in particular (Sengupta et al. 2020)-is particularly deleterious. Regrettably, appropriate management and maintenance are not always prioritized; Peteet et al. (2018) note that sediment starvation due to urban development in the New York City area has significantly impeded the resilience of coastal wetlands to sea level rise.

It is clear, therefore, that coastal wetlands buffer sea level rise and climate change and are important controlling elements in a wide range of physical and biogeochemical processes (Newton et al. 2020). Barbier (2019: 958) notes, however, that "...there is still skepticism among wetland regulators and coastal managers about how useful such valuation studies are'. Given their demonstrable value in terms of ecosystem services, the protection of coastal and estuarine wetlands must surely be considered an imperative. In this paper, following a brief review of the escalating threats to coastal wetlands that are increasingly a feature of the Anthropocene, we propose that a critical zone science (CZS) approach is best suited to facilitating the kind of integrated scientific research that is needed to develop a more holistic understanding of the behaviour of these complex systems. In order to facilitate their adequate protection and continued provision of ecosystem services, we argue that the current network of integrated science observatories (CZOs and their equivalents) has largely underplayed or ignored the importance of coastal and estuarine wetlands.

\section{Coastal and Estuarine Wetlands in the Anthropocene}

In the age of burgeoning anthropogenic disruption that has arguably seen the dawn of a new geological epoch - the Anthropocene - global environmental change has wrought impacts of increasing frequency and magnitude. Estuarine and coastal ecosystems are among the most vulnerable of all natural systems in which the full range of physical, chemical and biological processes are threatened by anthropogenic forces (Newton et al. 2020). For more than 7000 years, humans have '...profoundly impacted, degraded or destroyed...coastal wetlands' (Hopkinson et al. 2019, p. 37) both directly and indirectly. The scale and rate of these impacts have increased as, juxtaposed at the interface between land and sea, coastal wetlands are subject to stresses from both directions. Indeed, the world lost around half of its coastal wetlands altogether during the twentieth century ( $\mathrm{Li}$ et al. 2018). Examples of human impact on coastal wetlands from the recent literature indicate that the processes of disruption are at once diverse and widespread and include sea level rise 
Fig. 1 An illustration of the linkages that demonstrate the need for the valuation of coastal and estuarine environment ecosystem services.

Anthropogenic impacts drive coastal change and influence ecosystem structure and function, which in turn impact ecosystem services. Valuation is the means of considering the nature and scale of resultant losses (and gains), following which the drivers of change can be reassessed (after Barbier 2019)

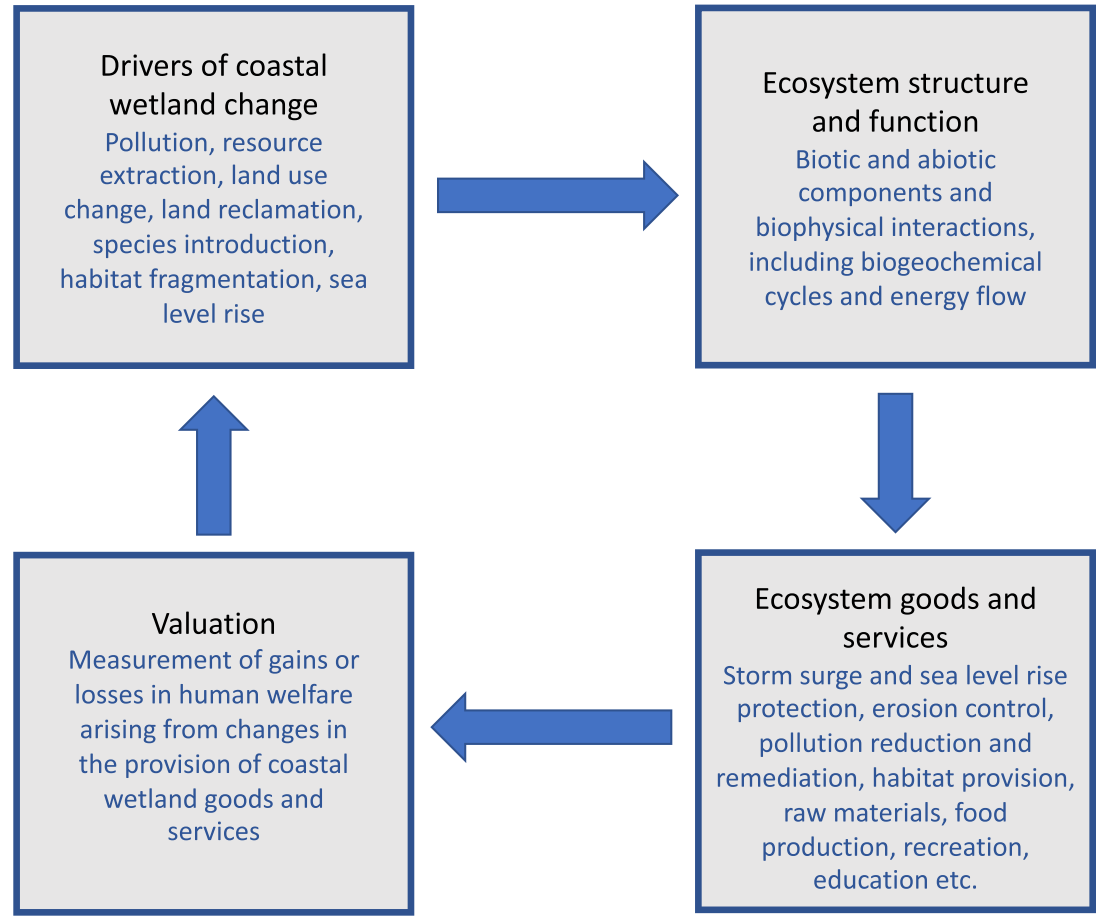

(Haywood et al. 2020), higher salinities (Yu et al. 2019), lower sediment fluxes due to reduced freshwater inflows (Cheng et al. 2019), pollution by heavy metals (Ye et al. 2020), organic compounds (Tang et al. 2020) and microplastics (Zhou et al. 2020), the introduction of invasive species (Yang 2019) and habitat loss and fragmentation (Bryan-Brown et al. 2020). Land reclamation projects have been especially prominent around the major coastal cities in Asia over the last two decades with considerable impact on coastal wetlands (Hu et al. 2018; Sengupta et al. 2020). Land is typically reclaimed for economic development but sometimes for coastal protection or even conservation, although there are often unanticipated and highly negative outcomes (Zhang et al. 2017; Yang et al. 2018b).

Newton et al. (2020) have recently presented an inclusive and comprehensive review of direct anthropogenic impacts on coastal wetlands. Here we emphasize the effects of human activities in the wider catchment on sedimentation patterns in coastal and estuarine environments to illustrate the need for a more integrated and holistic approach to research. Sediment dynamics are strongly impacted by changes, not only at or near the coast itself but also arising from upstream changes in land cover and in hydrological changes caused by reservoir construction. By way of example, the construction of the Three Gorges Dam (the largest impoundment in the world) has resulted in an array of hydrological, geomorphological and sedimentological responses and stimulated a substantial body of research on the downstream Yangtze (Changjiang)
River. Along with more than 50,000 other reservoirs in the catchment, the Three Gorges Dam has reduced downstream suspended sediment concentrations by 70 to $90 \%$ and induced major changes in sedimentation patterns in the estuary (Yang et al. 2018a). The markedly reduced fluvial sediment loads have, as expected, resulted in recession of the Yangtze delta (Luo et al. (2017), although impacts on the wider estuarine environment have not always been as anticipated (Zhu et al. 2019). Indeed, accretion of mudflats has actually increased in many localities around the Yangtze estuary due to lower annual discharge and reduced flood frequencies (Hu et al. 2019), a situation that has been further promoted through land reclamation (Sengupta et al. 2019).

It is therefore well recognized that, in addition to the localized impacts of human activity on a range of biophysical processes, activities in the wider catchment strongly influence patterns of sedimentation at the coast. Given that these anthropogenic forces threaten their longer-term sustainability and increased exposure to climate change and sea level rise, a more comprehensive and integrated approach to research on coastal and estuarine wetlands is clearly necessary.

\section{Towards a Critical Zone Science Approach to Coastal Wetlands Research}

Greater scientific attention than ever before is being paid to ecosystems associated with the near-surface layer, and indeed, 
in 2001, the National Research Council of the USA formalized the concept of the earth's critical zone (CZ) and established a number of observatories (CZOs: US National Research Council 2001; White et al. 2015) to this end. CZS is uniquely situated to analyse the complexity of processes that operate at multiple spatial and temporal scales in coastal and estuarine systems. As Minor et al. (2020) note, integrating the range of processes at the intersection of the atmosphere, hydrosphere/cryosphere, lithosphere and biosphere with anthropogenic disturbance '.. provides new opportunities to interpolate CZS across larger scales' ( $\mathrm{p} . \mathrm{x}$ ) but also, to investigate individual ecosystem types, such as those at the coast, with a more holistic approach.

The CZ is defined by the US Natural Research Council (2001) as ' ...the heterogeneous, near-surface environment in which complex interactions involving rock, soil, water, air, and living organisms regulate the natural habitat and determine the availability of life-sustaining resources'. There are clear benefits to adopting this approach towards understanding coastal and estuarine environments. The focus on integration, as well as an emphasis on functional processes and mechanisms, in which there is a strong mechanistic and quantitative element, is especially powerful. The CZ concept is often visualized as a three-dimensional block diagram, typically as a temperate forest-grassland ecosystem (see, e.g. Chorover et al. 2007), although any ecosystem type can be conceptualized in this way. The concept can, and indeed should, be applied to coastal and estuarine wetlands, although these systems have more complex energy and material flows arising from the fact that they are a product of terrestrial, fluvial and marine physical, ecological and biogeochemical processes that add considerable complexity that needs to be accounted for. For example, they are exposed to sea level rise and storm surges that are in turn associated with inundation, salinity intrusion and waterlogging. Moreover, as noted above, estuarine and coastal wetlands are strongly impacted by environmental changes that occur in the wider catchment in such a way that they are more accurately conceptualized as a kind of 'extended' CZ across a multifunctional landscape (Luo et al. 2019). Many of the processes characteristic of these systems are not typical of other terrestrial ecosystems, and if reductive modelling is applied, which has characterized the CZS approach (see, e.g. the effective energy mass transfer, EEMT, model of Rasmussen et al. 2011, 2015), then these additional components need to be incorporated into the model. Interestingly, human impact was not explicitly considered in the original CZ concept, although there are expanding efforts to include anthropogenic processes in CZ research (Minor et al. 2020). Figure 2 illustrates the additional complexity of estuarine environments from a CZS perspective as it is necessary to take into account a wide range of catchment processes as well as those more proximal to the systems themselves, including those associated with human activity.
Since coastal wetlands are a product of multiple interacting and dynamic environmental processes across time and space, an integrative approach to research on these ecosystems is indispensable in the context of increasing intensity of human impact. The $\mathrm{CZ}$ concept is a valuable conceptual framework and indeed a motivation, for future research and application of such a framework to vulnerable estuarine and coastal wetlands seems particularly appropriate. The need for integrated approaches is further emphasized in reflecting on the nature and scale of human impact at the coast and highlights the potential advantages of adopting the kind of holistic research that CZ thinking embodies. As noted by Lin et al. (2011), integrated, interdisciplinary and multiscale efforts are needed for effective management of vulnerable ecosystems, and the CZS approach offers a unifying framework.

Indeed, coastal and estuarine wetlands are multifaceted systems, and the coupling of material and energy fluxes that link sediments, geomorphology, hydrodynamics and biogeochemical processes ('ecomorphodynamics', see d'Alpaos et al. 2019) introduces considerable complexity, the significance of which is heightened by the fact that they are characterized by high levels of both biodiversity and productivity. Coastal ecosystems represent 'hot spots' for processing and transforming both materials and energy (Ward et al. 2020). In general, these ecosystems act globally as a carbon sink and form an important component of the so-called Blue Carbon cycle (McCreadle et al. 2017). Among the numerous material and energy fluxes, it is arguably most important to obtain accurate assessments of the nature and scale of carbon sequestration in coastal and estuarine ecosystems, not least in situations where such information is used to frame management practice (Villa and Bernal 2018). Indeed, coastal wetlands play a disproportionately significant role in the global carbon cycle (Hopkinson et al. 2019; Rogers et al. 2019). Recent developments in methodology, more specifically the use of eddy covariance to estimate carbon flux, have necessitated a reassessment of the magnitude of their function ( $\mathrm{Lu}$ et al. 2017; Mitsch and Mander 2018). For example, Forbrich et al. (2018) used the micrometeorological flux technique to measure primary productivity in salt marshes on the Plum Island Long-term Ecological Research (LTER) site in northeastern Massachusetts, over a 5-year period. It transpires that net carbon uptake in this case was substantially lower than previously published estimates for similar ecosystems, although global carbon budgets are not yet available that take into account the more nuanced understanding that emerges from eddy covariance studies. The fact that carbon flux not only varies spatially but also interannually and seasonally (see Gao et al. 2018) adds even more complexity and further research to constrain the magnitude of this important process at high temporal resolution is clearly still lacking. Moreover, there are many other kinds of material and energy fluxes that remain poorly understood at the coastal interface, and their 


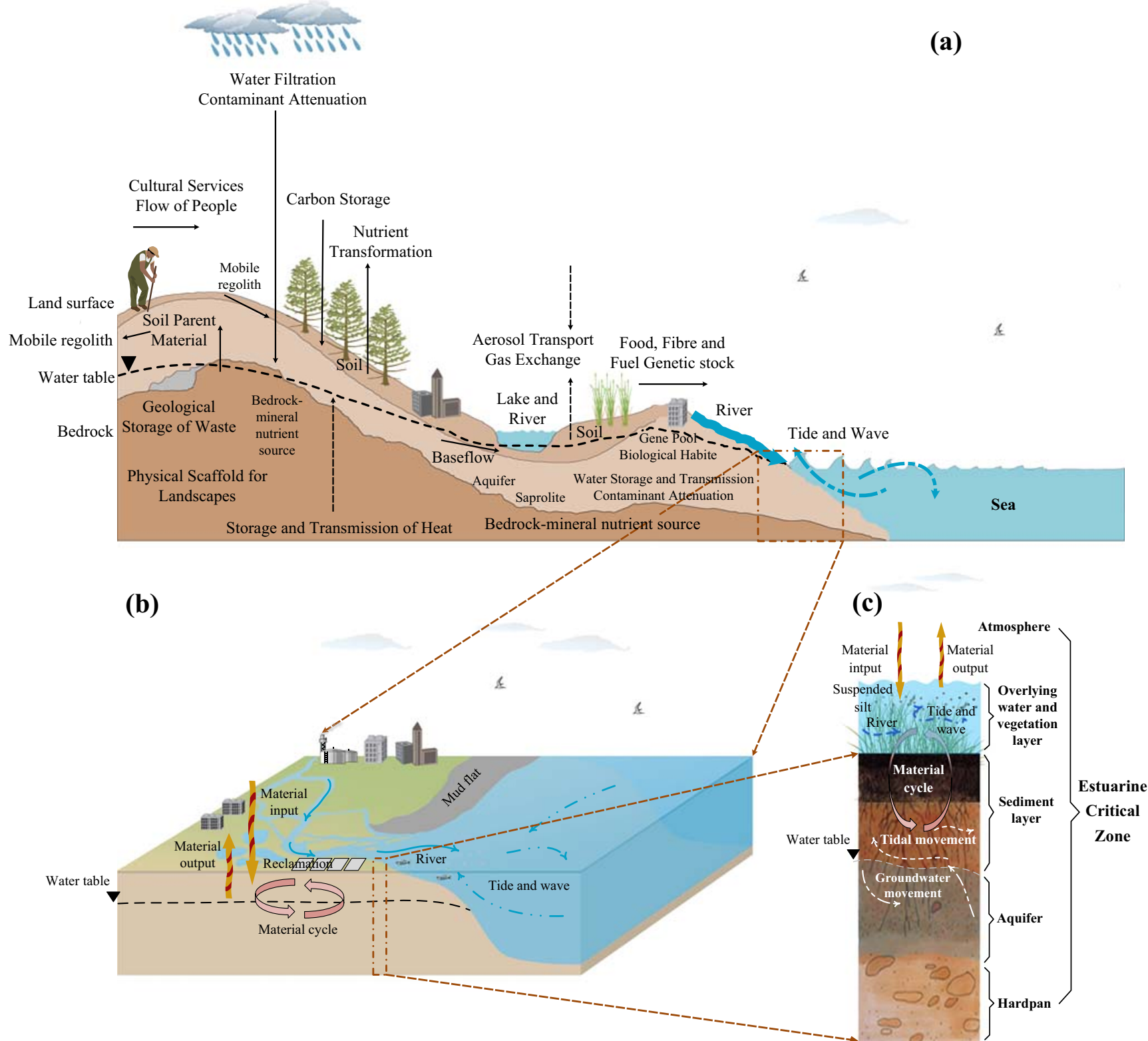

Fig. 2 Coastal and estuarine ecosystems as considered from a CZS perspective, indicating the diverse array of driving forces. Note that the typical two-dimensional illustration of the $\mathrm{CZ}$ (c) has to be extended into

meaningful incorporation into Earth system models is imperative, albeit very challenging (Ward et al. 2020). Adopting a CZS modelling approach would therefore seem warranted, especially if conducted at an intensively studied long-term environmental observatory site.

What, then, are the advantages of CZS as a means of understanding coastal and estuarine wetlands? Although it might seem self-evident, a complex environmental system cannot be understood properly without due recognition of the interactions among its various physical, chemical and biological processes and their resultant patterns. The systems approach that is most commonly employed by scientists to analyse flows of energy and mass (Giardino and Houser 2015) allows for the the broader coastal ecosystem (b) and the catchment as a whole (a). The inclusion of human activities within the concept, as suggested by Minor et al. (2020), is also illustrated

development and refinement of models that better explain these processes in the $\mathrm{CZ}$ - all the more crucial for the fact that coastal wetlands are subject to increasing anthropogenic pressures. There is much to be gained by adopting the broader spatial and temporal framework that CZS fosters (see Field et al. 2015), not only because this improves our understanding of how systems actually work, but how they respond to disturbance, and this has considerable application for policy (Montanarella and Panagos 2015), management (Richardson and Kumar 2017), education (Wymore et al. 2017) and environmental sustainability in general (Luo et al. 2019), as well as particular responses of ecosystem attributes to perturbation (Weintraub et al. 2019). A CZ approach enables the 
realization of simultaneous long-term observation and systematic analysis of coupled physical, chemical and biological processes across multi-interface and multi-temporal scales in order to reveal the underlying mechanisms controlling the evolution of coastal wetlands. Considering these processes across the entire range of spatial scales, from the molecular to catchment, is essential but poorly understood, and the range of timescales over which these interconnections operate has not yet been examined (Ward et al. 2020). An integrated CZS approach would certainly help to address this shortfall. There are, then, a number of clear advantages to adopting such a CZ framework over more conventional approaches to research on estuarine and coastal wetlands. These include the benefit of considering a wider range of spatiotemporal scales of analysis, literally from the molecular to continental scale and from geological timescales to the present and future through what Guo and Lin (2016) conceptualize as a structure that integrates 'deep time', 'deep depth' and 'deep coupling'.

The CZS approach is also valuable in developing and directing attention towards strategic research questions. Lin et al. (2011) highlight a number of key CZS themes, including water, carbon, nutrient and energy cycles, sediment accumulation, erosion and redistribution (especially in relation to land use change, sea level rise and climate change), coupled with geomorphological, hydrological, pedological and ecological processes. All of these issues are of course important, but the question now arises: what steps can be taken to encourage CZS thinking in relation to coastal and estuarine wetlands in particular?

\section{Representation of Coastal Wetlands in Environmental Observatories}

Formally constituted CZOs are intended to fulfill a role as prototypes for long-term observation and as benchmarks against which to assess the nature and extent of environmental change. CZOs have now been established in many different ecosystem types globally in order to support and coordinate the development of new knowledge towards sustainable management of the earth's critical zone (Banwart et al. 2013). These provide the focus for long-term observational, measurement, monitoring and experimental analyses that are at the core of CZS and have considerable power in enhancing interdisciplinary research (Gran et al. 2019).

Analysis of the inventory of CZO localities listed by Banwart et al. (2013) reveals that the coastline in general is markedly under-represented in the global array of sites. Most of the CZOs are exclusively terrestrial (e.g. North Central Great Plains, North Dakota), and even in cases where entire watersheds are the focus (e.g. Reynolds Creek, SW Idaho), in most instances, these are secondary catchments with no direct outlet to the sea. Some of the island observatories (e.g.
Galapagos, Guadeloupe, or Rivière des Pluies, Réunon) do, of course, have coastlines, but coastal wetlands do not appear to be an explicit focus of the associated research; they are certainly very much under-represented.

The CZS approach to research and monitoring may, in essence, not be restricted only to those environmental observatories that are formally classified as CZOs. Several other types of observatories can be considered functional equivalents of CZOs or comparable in terms of objectives. These include Long-Term Ecological Research (LTER) sites (Huang et al. 2020) in the USA and eLTER in Europe (Mollenhauer et al. 2018) which are further networked internationally through iLTER (Mirtl et al. 2018). In addition, there are a number of national-scale initiatives with compatible aims and characteristics, including the National Ecological Observatory Network, (NEON) in the USA (Tolleson 2011), the Chinese Ecosystem Research Network (Fu et al. 2010), the German Terrestrial Environmental Observatories (TERENO, Kiese et al. 2018), OZCAR in France (Gaillardet et al. 2018), the UK Environmental Change Network (Sier and Monteith 2016) and the SuperSite network (Karan et al. 2016) and TERN (Cleverly et al. 2019) in Australia. All provide a focus for interdisciplinary research teams to measure, monitor, experiment and model the range of interconnected processes that operate in the vertical, as well as lateral dimensions - and over time. The Critical Zone Exploration Network (CZEN: https:// www.czen.org/, accessed 1st September 2020) includes examples of all of the above programs, and although the list of environmental observatories included in CZEN does not include all long-term monitoring and research sites globally, it provides a useful global perspective on their spatial distribution and ecosystem type representation. Based on the CZEN database, Supplementary Material Table 1 provides basic details of the characteristics of a wider network of CZOs or their functional equivalents. The primary aim of the CZEN is stated as promoting and developing a network of observatories for investigating $\mathrm{CZ}$ processes and facilitating access to data on environmental attributes of the sites along gradients of time, lithology, human disturbance, biological activity and topography. The CZEN network provides information on 246 observatories including those affiliated with the evolving formal CZO group, as well as a wide range of other formally established sites that are distributed across all the continents. Considerable spatial unevenness is, however, evident in their distribution. For example, the USA hosts $130(53 \%)$ of these observatories, while China (23 sites), France (15), Australia (13) and Germany (11) are the only other countries recorded as hosting more than ten. Europe and North and Central America together account for almost three-quarters of all the observatory localities. Vegetation types that predominate in the observatories are variable, but mixed temperate forest $(76 ; 30 \%)$, agriculture $(53 ; 21.5 \%)$ and evergreen and coniferous forest $(47 ; 19 \%)$ are most strongly 
represented. By far, the majority of habitats characterizing the observatories are inland terrestrial $(225 ; 89 \%)$, with only 24 (less than $10 \%$ ) focusing on coastal localities, of which just three sites (the Smithsonian Environmental Research Station, Georgia Coastal Ecosystems LTER, and Plum Island Ecosystems LTER) explicitly focus on estuarine habitats.

Notwithstanding the wide coverage of environmental observatories in the CZEN inventory, it is not comprehensive, and reflections on some of the other major observatory networks are instructive. For example, of the $81 \mathrm{NEON}$ sites, the vast majority are terrestrial, and only one (Utqiagivik - BARR in northern Alaska) focuses on the coast. The LTER network, initiated in 1980 by the US National Science Foundation, does have greater representation of coastal and estuarine habitats. Of the 28 US LTER sites listed (https://lternet.edu/site/ accessed 1st September 2020), six are located within coastal ecosystems, two of which are devoted to estuarine habitats; a further four are essentially marine, including one coral reef site. Founded in 1993, the International Long-Term Ecological Research Network (ILTER) now represents more than 40 active LTER networks globally (Mirtl et al. 2018) and lists 1198 sites and platforms (https://deims.org/search/sites accessed 1 September 2020). Of these sites, 63 (5\%) are located in coastal situations, of which just six are explicitly devoted to estuarine habitats. Nevertheless, reflecting on the characteristics of environmental observatories globally, the overall picture emerging is that estuarine and coastal wetlands, which are among the most valuable - and certainly the most threatened of all ecosystems - are very markedly under-represented.

\section{Leveraging the Advantages of Environmental Observatories}

The evident lack of coverage of estuarine and coastal wetlands among the various environmental observatories is all the more problematic given the research, monitoring, modelling, management and educational potential of such sites. Increasing the number of observatories devoted to such habitats would doubtless improve our understanding of these vulnerable systems, especially if a CZS approach was incorporated, especially if coordinated through the network of CZOs or their equivalents. As Brantley et al. (2017) note, CZS involves, inter alia, synthesizing research across disciplines, developing long-term data sets and stimulating new hypotheses and models. Such an approach requires systematic and coordinated research that is a characteristic of environmental observatories, albeit that integrating and harmonizing their respective outputs remains a major challenge (Mollenhauer et al. 2018). Greater coordination and integration of monitoring and observation stations is clearly required, and as Weintraub et al. (2019) demonstrate in the case of research on soil organic matter, rationalizing data measurement standards can ensure complementarity and coordination between the major global observatory networks such as CZO, NEON and LTER. Harnessing the potential of environmental observatories to improve Earth system models also necessitates better integration between sites (Baatz et al. 2018), with the added benefit of optimizing resources (Hinckley et al. 2016). Using Mexico as an example, Villareal et al. (2019) propose a framework to improve the efficiency and effectiveness of environmental observatories and suggest that such a model could be applied more generally. Not only do such networks encourage researchers to keep pace with technological and conceptual scientific advances (Huang et al. 2020), they also foster interaction and communication with society at large which is essential to retaining their relevance and, accordingly, funding (Richter et al. 2018).

Although, as noted above, coastal environments in general are not well represented in the various global and national environmental observatories, in particular the CZO network, the ILTER system does provide a platform on which to develop the support and knowledge necessary to address the multiple threats facing them in the Anthropocene. The 63 coastal and 52 marine sites in the ILTER network (ILTER-CMS) employ standard data protocols, are committed to free and open data sharing and interoperability and have the capability to develop multiscale syntheses of the sort that characterize CZS (Muelbert et al. 2019). These sites have existing research infrastructure and resources that have the potential to contribute greatly to a deeper understanding of the associated biological, chemical, and physical environmental processes. Furthermore, the long time span of some of these sites opens up opportunities to assess global trends against the benchmark of natural variation. In short, the inclusion of more coastal and estuarine sites in one or more of the major environmental observatory networks, more especially if the research and monitoring is integrated according to the principles of CZS, would go some way towards promoting the long-term sustainability of these crucial but highly threatened ecosystems.

\section{Conclusions}

There is a need for more integrated coastal and estuarine ecosystem studies, and CZS represents a potentially valuable theoretical framework. The stark deficiency in representation of coastal and estuarine wetlands habitats in the CZO and broader environmental observatory network must surely be addressed in order to support integrated, quantitative research that is required to better understand and, ultimately, protect these vulnerable environments and the ecosystem services they provide. There has clearly been much recent research interest in estuarine and coastal wetlands because of their value and vulnerability, and doubtless advances have been made 
in our understanding of particular elements of process and pattern in what are arguably among the most vulnerable of all ecosystem types. However, we suggest that a CZS approach would better facilitate a deeper understanding of the relationships and feedbacks among the layers of these complex systems, especially in light of ongoing human-induced environmental pressures. Nevertheless, the paucity of estuarine and coastal wetland coverage in the global environmental observatory network is conspicuous and should be addressed urgently to enable the diverse research benefits of such sites to be realized. The development of a formal CZO (or its de facto equivalent) for these habitats would leverage several advantages (Lin et al. 2011). For example, environmental observatories facilitate funding to provide research infrastructure, attract high profile scientists and allow data sharing and complex model development. If appropriate research protocols can be established (Firbank et al. 2017), this further enhances coordination and enables meaningful comparison between observatory sites and amplifies the value of research results. As Ward et al. (2020: 11) note '.. a predictive understanding of the role of coastal interfaces on a global scale is not a task that can be achieved by any one agency, institution or researcher, but requires collaboration across scales, disciplines, cultures and funding agencies'. The devotion of at least one CZO to integrated research on coastal and estuarine wetland habitat would not address all these challenges, but it would surely be a step in the right direction.

Acknowledgments We thank Gao Dengzhou, School of Geographical Sciences, East China Normal University, for Fig. 2.

Funding This study was funded by the National Natural Science Foundation of China (41761144062, 41730646, 41725002, 41771506) and by the National Research Foundation of South Africa (Grant No: 110776). Additional funding for this work was provided by the Yangtze Delta Estuarine Wetland Station of East China Normal University (ECNU).

Open Access This article is licensed under a Creative Commons Attribution 4.0 International License, which permits use, sharing, adaptation, distribution and reproduction in any medium or format, as long as you give appropriate credit to the original author(s) and the source, provide a link to the Creative Commons licence, and indicate if changes were made. The images or other third party material in this article are included in the article's Creative Commons licence, unless indicated otherwise in a credit line to the material. If material is not included in the article's Creative Commons licence and your intended use is not permitted by statutory regulation or exceeds the permitted use, you will need to obtain permission directly from the copyright holder. To view a copy of this licence, visit http://creativecommons.org/licenses/by/4.0/.

\section{References}

Baatz, R., P.L. Sullivan, L. Li, S. Weintraub, H.W. Loescher, M. Mirtl, P.M. Groffman, D.H. Wall, M. Young, T. White, H. Wen, S. Zacharias, I. Kühn, J. Tang, J. Gaillardet, I. Braud, A.N. Flores, P. Kumar, H. Lin, T. Ghezzehei, J. Jones, H.L. Ghotz, H. Vereecken, and K. van Looy. 2018. Steering operational synergies in terrestrial observation networks: Opportunity for advancing earth system dynamics modelling. Earth System Dynamics 9 (2): 593-609.

Banwart, S.A., Chorover, J., Gaillardet, J., Sparks, D. , White, T., Anderson, S., Aufdenkampe, A., Bernasconi, S., Brantley, S.L, Chadwick, O., Dietrich, W.E., Duffy, C., Goldhaber, M., Lehnert, K., Nikolaidis, N.P. and Ragnarsdottir, K.V. 2013 Sustaining Earth's critical zone: Basic science and interdisciplinary solutions for global challenges. Sheffield: University of Sheffield, UK.

Barbier, E.B. 2015. Valuing the storm protection service of estuarine and coastal ecosystems. Ecosystem Services 11: 32-38.

Barbier, E.B. 2019. The value of coastal wetland ecosystem services. In Coastal wetlands: An integrated ecosystem approach, ed. M.E. Perillo, E. Wolanksi, D.R.C. Cahoon, and C.S. Hopkinson, 2nd ed., 947-964. Amsterdam, The Netherlands: Springer.

Barbier, E.B., S.D. Hacker, C. Kennedy, E.W. Koch, A.C. Stier, and B.R. Silliman. 2011. The value of estuarine and coastal ecosystem services. Ecological Monographs 81 (2): 169-193.

Brantley, S.L., W.H. McDowell, Dietrich, W.E. White, T.S. Kumar, S.P. Anderson, J. Chorover, K.A. Lohse, R.C. Bales, D.D. Richter, G. Grant, and J. Gaillardet. 2017. Designing a network of critical zone observatories to explore the living skin of the terrestrial. Earth Earth Surface Dynamics 5 (4): 841-860.

Bryan-Brown, D.N., R. Connolly, D.R. Richards, F. Adame, D.A. Friess, and C.J. Brown. 2020. Global trends in mangrove forest fragmentation. Scientific Reports 10 (1): 7117.

Cheng, Z., X.H. Wang, I. Jalon-Rojas, and Y. Liu. 2019. Reconstruction of sedimentation changes under anthropogenic influence in a medium-scale estuary based on a decadal chronological framework. Estuarine, Coastal and Shelf Science 227: 106295.

Chorover, J., R. Kretzschmar, F. Garcia-Pichel, and D.L. Sparks. 2007. Soil biogeochemical processes within the critical zone. Elements 3 (5): 321-326.

Cleverly, J., D. Eamus, W. Edwards, M. Grant, M.J. Grundy, A. Held, M. Karan, A.J. Lowe, S.M. Prober, B. Sparrow, and B. Morris. 2019. TERN, Australia's land observatory: Addressing the global challenge of forecasting ecosystem responses to climate variability and change. Environmental Research Letters 14 (9): 095004.

Comte, A., L.H. Pendleton, D. Bailly, and E. Quillérou. 2019. Conceptual advances on global scale assessments of vulnerability: Informing investments for coastal populations at risk of climate change. Marine Policy 99: 391-399.

d'Alpaos, A., S. Lanzone, A. Rinaldo, and M. Marani. 2019. Salt-marsh ecogeomorphological dynamics and hydrodynamic circulation. In Coastal wetlands: An integrated ecosystem approach, ed. M.E. Perillo, E. Wolanksi, D.R.C. Cahoon, and C.S. Hopkinson, 2nd ed., 189-220. Amsterdam, The Netherlands: Springer.

Field, J.P., D.D. Breshears, D.J. Law, J.C. Villegas, L. López-Hoffman, P.D. Brooks, J. Chorover, G.A. Barron-Gafford, R.E. Gallery, M.E. Litvak, R.A. Lybrand, J.C. McIntosh, T. Meixner, G.-Y. Niu, S.A. Papuga, J.D. Pelletier, C. Rasmussen, and P.A. Troch. 2015. Critical zone services: Expanding context, constraints, and currency beyond ecosystem services. Vadose Zone Journal 14 (1): 1-14.

Firbank, L.G., C. Bertora, D. Blankman, and delle Vedove, G., Frenzel, M., Grignani, C., Groner, E., Kertesz, M., Krab, E.J., Matteucci, G., Menta, C., Mueller, C.W., Stadler, J., and Kunin, W. 2017. Towards the coordination of terrestrial ecosystem protocols across European research infrastructures. Ecology and Evolution 7: 3867-3975.

Forbrich, I., A.E. Giblin, and C.S. Hopkinson. 2018. Constraining marsh carbon budgets using long-term $\mathrm{C}$ burial and contemporary atmospheric $\mathrm{CO}_{2}$ fluxes. Journal of Geophysical Research: Biogeosciences 123 (3): 867-878.

Fu, B., S. Li, X. Yu, P. Yang, G. Yu, R. Feng, and X. Zhang. 2010. Chinese ecosystem research network: Progress and perspectives. Ecological Complexity 7 (2): 225-233. 
Gaillardet, J., I. Braud, F. Hankard, S. Anquetin, O. Bour, N. Dorfiger, J.R. de Dreuzy, S. Galle, C. Galy, S. Gogo, L. Gourcy, F. Habets, F. Laggoun, et al. 2018. OZCAR: The French network of critical zone observatories. Vadose Zone Journal 17: 1-24.

Gao, Y., Z. Ouyang, C. Shao, H. Chu, Y.-J. Su, H. Guo, J. Chen, and B. Zhao. 2018. Field observation of lateral detritus carbon flux in a coastal wetland. Wetlands 38 (3): 613-625.

Giardino, J.R., and C. Houser, eds. 2015. Principles and dynamics of the critical zone. Amsterdam, The Netherlands: Elsevier.

Gran, K.B., C. Dolph, A. Baker, M. Bevis, S.J. Cho, J.A. Czuba, B. Dalzell, M. Danesh-Yazdi, A.T. Hansen, S. Kelly, Z. Lang, J. Schwenk, P. Belmont, J.C. Finlay, P. Kumar, S. Rabotyagov, G. Roehrig, P. Wilcock, and E. Foufoula-Georgious. 2019. The power of environmental observatories for advancing multidisciplinary research, outreach, and decision support: The case of the Minnesota Basin. Water Resources Research 55 (4): 3576-3592.

Guo, L., and H. Lin. 2016. Critical zone research and observations: Current status and future perspectives. Vadose Zone Journal 15 (9): $1-14$

Haywood, B.J., M.P. Hayes, J.R. White, and R.L. Cook. 2020. Potential fate of wetland soil carbon in a deltaic coastal wetland subjected to high relative sea level rise. Science of the Total Environment 711: 135185

Highfield, W.E., S.D. Brody, and C. Shepard. 2018. The effects of estuarine wetlands on flood losses associated with storm surge. Ocean and Coastal Management 157: 50-55.

Hinckley, E.S., S.P. Anderson, J.S. Baron, P.D. Blanken, G.B. Bonan, W.D. Bowman, S.C. Elemendorf, N. Fierer, A.M. Fox, K.J. Goodman, K.D. Jones, D.L. Lombarozzi, C.K. Lunch, J.C. Neff, M.D. Sanclements, K.N. Suding, and W.R. Wieder. 2016. Optimizing available network resources to address questions in environmental biogeochemistry. BioScience 66 (4): 317-326.

Hopkinson, C.S., E. Wolanksi, M.M. Brinson, et al. 2019. Coastal wetlands: A synthesis. In Coastal wetlands: An integrated ecosystem approach, ed. M.E. Perillo, E. Wolanksi, D.R.C. Cahoon, and C.S. Hopkinson, 2nd ed., 1-75. Amsterdam, The Netherlands: Springer.

Hu, C., Z.-J. You, H.-Y. Mao, and X.-M. Hu. 2018. Assessing impacts of large-scale coastal land reclamation on marine environment on the coast of China. Journal of Coastal Research 85: 1486-1490.

Hu, M.-Y., Z.-M. Ge, Y.-L. Li, S.-H. Li, L.-S. Tan, L.-N. Xie, Z.-J. Hu, T.-Y. Zhang, and X.-L. Li. 2019. Do short-term increases in river and sediment discharge determine the dynamics of coastal mudflat and vegetation in the Yangtze estuary? Estuarine, Coastal and Shelf Science 220: 176-184.

Huang, T.-Y., M.R. Downs, J. Ma, and B. Zhao. 2020. Collaboration across time and space in the LTER network. BioScience 70 (4): 353-364.

Karan, M., M. Liddell, S.M. Prober, S. Arndt, J. Beringer, M. Boer, J. Cleverly, D. Eamus, P. Grace, E. van Gorsel, J.-M. Hero, L. Hurley, C. Macfarland, D. Metclafe, W. Meyer, E. Pendall, A. Sebastican, and T. Wardlaw. 2016. The Australian SuperSite network: A continental, long-term terrestrial ecosystem observatory. Science of the Total Environment 568: 1263-1274.

Kiese, R., B. Fersch, C. Baessler, C. Brosy, B. Butterbach, C. Chwala, M. Dannenmann, J. Fu, R. Gasche, R. Grote, C. Jahn, J. Klatt, H. Kunstmann, M. Mauder, T. Rödiger, G. Smiatek, M. Soltani, R. Steinbrecher, I. Völksch, J. Werhahn, B. Wolf, M. Zeeman, and H.P. Schmid. 2018. The TERENO pre-alpine observatory: Integrating meteorological, hydrological, and biogeochemical measurements and modeling. Vadose Zone Journal 17: 180060.

Kirwan, M.L., and J.P. Megonigal. 2013. Tidal wetland stability in the face of human impacts and sea level rise. Nature 504 (7478): 53-60.

Li, X., R. Bellerby, C. Craft, and S.E. Widney. 2018. Coastal wetland loss, consequences, and challenge for restoration. Anthropocene Coasts 1: 1-15.
Lin, H., J.W. Hopmans, and D.D. Richter. 2011. Interdisciplinary sciences in a global network of critical zone observatories. Vadose Zone Journal 10 (3): 781-785.

Lu, W., J. Xiao, F. Liu, Y. Zhang, C. Liu, and G. Lin. 2017. Contrasting ecosystem $\mathrm{CO} 2$ fluxes of inland and coastal wetlands: A metaanalysis of eddy covariance data. Global Change Biology 23 (3): $1180-1198$.

Luo, X.X., S.L. Yang, R.S. Wang, Y. Zhang, and P. Li. 2017. New evidence of Yangtze delta recession after closing of the three gorges dam. Scientific Reports 7 (1): 41735.

Luo, Y., Y. Lü, B. Fu, P. Harris, L. Wu, and A. Comber. 2019. When multi-functional landscape meets critical zone science: Advancing multi-disciplinary research for sustainable human well-being. National Science Review 6 (2): 349-358.

McCreadle, P.I., D.A. Nielson, J.J. Kelleway, T.B. Atwood, J.R. Seymour, K. Petrou, R.M. Connolly, A.C.G. Thomson, S.M. Trevathan-Tackett, and P.J. Ralph. 2017. Can we manage coastal ecosystems to sequester more blue carbon? Frontiers in Ecology and the Environment 15 (4): 206-213.

Minor, J., J.K. Pearl, M.L. Barnes, T.R. Colella, P.C. Murphy, S. Mann, and G.A. Barron-Gafford. 2020. Critical zone science in the Anthropocene: Opportunities for biogeographic and ecological theory and praxis to drive earth science integration. Progress in Physical Geography 44 (1): 50-69.

Mirtl, M., E.T. Borer, I. Djukic, M. Forsius, H. Haubold, W. Hugo, J. Jourdan, D. Lindenmayer, W.H. McDowell, H. Muraoka, D.E. Orenstein, J.C. Pauw, J. Petersell, H. Shibata, and C. Wohner. 2018. Genesis, goals and achievements of Long-Term Ecological Research at the global scale: a critical review of ILTER and future directions. Science of the Total Environment 626: 1439-1462.

Mitsch, W.J., and Ü. Mander. 2018. Wetlands and carbon revisited. Ecological Engineering 114: 1-6.

Mollenhauer, H., M. Kasner, P. Haase, J. Peterseil, C. Wohner, M. Frenzel, M. Mirtl, R. Schima, J. Bumberger, and S. Zacharias. 2018. Long-term environmental monitoring infrastructures in Europe: Observations, measurements, scales, and socio-ecological representativeness. Science of the Total Environment 624: 968-978.

Montanarella, L., and P. Panagos. 2015. Policy relevance of critical zone science. Land Use Policy 49: 86-91.

Montgomery, J.M., K.R. Bryan, J.C. Mullarney, and E.M. Horstman. 2019. Attenuation of storm surges by coastal mangroves. Geophysical Research Letters 46 (5): 2680-2689.

Muelbert, J.H., N.J. Nidzieko, A.T.R. Acosta, S.E. Beaulieu, A.F. Bernadino, E. Bolkova, T.G. Bornman, B. Cataletto, K. Deneudt, E. Eliason, A. Kraberg, M. Nakaoka, A. Pugnetti, O. Ragueneau, M. Scharfe, T. Soltwedel, H.M. Sosik, A. Stanisci, K. Stefanova, P. Stéphan, A. Stier, J. Wikner, and A. Zingone. 2019. ILTER The international long-term ecological research network as platform for global coastal and ocean observation. Frontiers in Marine Science 6: 527.

Newton, A., J. Icely, S. Cristina, G.M.E. Perillo, R.E. Turner, D. Ashan, S. Cragg, Y. Luo, C. Tu, Y. Li, H. Zhang, R. Ramesh, D.L. Forbes, C. Solidoro, B. Bejaoui, S. Gao, R. Pastres, H. Kelsey, D. Taillie, N. Nhan, A.C. Brito, R. de Lima, and C. Kuenzer. 2020. Anthropogenic, direct pressures on coastal wetlands. Frontiers in Ecology and Evolution 8: 144.

Osland, M.J., N. Enwright, R.H. Day, and T.W. Doyle. 2013. Winter climate change and coastal wetland foundation species: Salt marshes vs. mangrove forests in the southeastern United States. Global Change Biology 19 (5): 1482-1494.

Ouyang, X., S.-Y. Lee, R.M. Connolly, and M.J. Kainz. 2018. Spatiallyexplicit valuation of coastal wetlands for cyclone mitigation in Australia and China. Scientific Reports 8 (1): 3035.

Peteet, D.M., J. Nichols, T. Kenna, C. Chang, J. Browne, M. Reza, S. Kovari, L. Liberman, and S. Storm-Protz. 2018. Sediment starvation destroys New York City marshes resistance to sea level rise. 
Proceedings of the National Academy of Sciences 115 (41): 1028110286.

Rasmussen, C., P.A. Troch, J. Chorover, P. Brooks, J. Pelletier, and T.E. Huxman. 2011. An open system framework for integrating critical zone structure and function. Biogeochemistry 102 (1): 15-29.

Rasmussen, C., J.D. Pelletier, P.A. Troch, T.L. Swetnam, and J. Chorover. 2015. Quantifying topographic and vegetation effects on the transfer of energy and mass to the critical zone. Vadose Zone Journal 14 (11): 1-16.

Rezale, A.M., J. Loerzei, and C.M. Ferreira. 2020. Valuing natural habitats for enhancing coastal resilience: Wetlands reduce property damage from storm surge and sea level rise. PLoS One 15 (1): e0226275.

Richardson, M., and P. Kumar. 2017. Critical zone services as environmental assessment criteria in intensively managed landscapes. Earth's Future 5 (6): 617-632.

Richter, D.D., S.A. Billings, P.M. Groffman, E.F. Kelly, K.A. Lohse, W.H. McDowell, T.S. White, S. Anderson, D.D. Baldocchi, S. Banwart, S. Brantley, J.J. Braum, Z.S. Brechelsen, C.W. Cook, H.E. Hartnett, S.E. Hobbie, J. Gaillardet, E. Jobaggy, H.F. Jungkunst, C.E. Kazanski, J. Krishnaswamy, D. Markewitz, K.O. O’Neill, C.S. Riebe, P. Schroeder, C. Siebe, W.L. Silver, A. Thompson, A. Verhoef, and G. Zhang. 2018. Ideas and perspectives: Strengthening the biogeosciences in environmental research networks. Biogeosciences 15 (15): 4815-4832.

Rogers, K., J.J. Kelleway, N. Saintilan, P. Megonigal, J.B. Adams, J.R. Holmquist, M. Lu, L. Schile-Beers, A. Zawadzki, D. Mazumder, and C.D. Woodroffe. 2019. Wetland carbon storage controlled by millennial-scale variation in relative sea level rise. Nature 567 (7746): 91-95.

Schoutens, K., M. Heuner, V. Minden, T. Schulte Ostermann, A. Sillinski, J.P. Belliard, and S. Temmerman. 2019. How effective are tidal marshes as nature-based shoreline protection throughout seasons? Limnology and Oceanography 64 (4): 1750-1762.

Sengupta, D., R. Chen, M.E. Meadows, Y.R. Choi, A. Banerjee, and Z. Xia. 2019. Mapping trajectories of coastal land reclamation in nine deltaic megacities using Google Earth Engine. Remote Sensing 11: 2621.

Sengupta, D., R. Chen, M.E. Meadows, and A. Banerjee. 2020. Gaining or losing ground? Tracking Asia's hunger for 'new' coastal land in the era of sea level rise. Science of the Total Environment 732: 13920.

Sier, A., and D. Monteith. 2016. The UK environmental change network after twenty years of integrated ecosystem assessment: Key findings and future perspectives. Ecological Indicators 68: 1-12.

Sutton-Grier, A.E., and P.A. Sandifer. 2019. Conservation of wetlands and other coastal ecosystems: A commentary on their value to protect biodiversity, reduce disaster impacts, and promote human health and well-being. Wetlands 39 (6): 1295-1302.

Tang, D., X. Liu, H. He, Z. Cui, H. Gan, and Z. Xia. 2020. Distribution, sources and ecological risks of organochlorine compounds (DDTs, HCHs and PCBs) in surface sediments from the Pearl River estuary, China. Marine Pollution Bulletin 152: 110942.

Tolleson, J. 2011. US launches eco-network. Nature 476: 135.

US National Research Council. 2001. Basic research opportunities in the earth sciences. Washington DC: National Academies Press.

Vásquez-González, C., P. Moreno-Casasola, L.A. Peralta-Palaez, and I. Espejel. 2019. The value of coastal wetland flood prevention lost to urbanization on the coastal plain of the Gulf of Mexico: An analysis of flood damage by hurricane impacts. International Journal of Disaster Risk Reduction 37: 101180.

Villa, J.A., and B. Bernal. 2018. Carbon sequestration in wetlands, from science to practice: An overview of the biogeochemical process, measurement methods and policy framework. Ecological Engineering 114: 115-128.
Villareal, S., M. Guevara, D. Alcaraz-Segura, and R. Vargas. 2019. Optimizing an environmental observatory network design using publicly available data. Journal of Geophysical Research: Biogeosciences 124 (7): 1812-1826.

Ward, N.D., J.P. Megonigal, B. Bond-Lamberty, V.L. Bailey, D. Butman, E.A. Canuel, V.L. Diefenderfer, N.K. Ganju, M.A. Goñi, E.B. Graham, C.S. Hopkinson, T. Khangaonkar, J.A. Langley, N.G. McDowell, A.N. Myers-Pigg, R.B. Neumann, C.L. Osburn, R.M. Price, J. Rowland, A. Sengupta, M. Simard, P.E. Thornton, M. Tzortziou, R. Vargas, P.B. Weisenhorn, and L. Windham-Myers. 2020. Representing the function and sensitivity of coastal interfaces in earth system models. Nature Communications 11 (1): 2458.

Weintraub, S.R., A.N. Flores, W.R. Wieder, D. Sihi, C. Cagnarini, D.R. Potma Gonçalves, M.H. Young, L. Li, Y. Olshansky, R. Baatz, P. Sullivan, and P. Groffman. 2019. Leveraging environmental research and observation networks to advance soil carbon science. Journal of Geophysical Research: Biogeosciences 124 (5): 1047 1055.

White, T., S. Brantley, S. Banwart, J. Chrover, W. Dietriech, L. Derry, K. Lohse, S. Anderson, Aufdendkampe, R. Bales, P. Kumar, D. Richter, and B. McDowell. 2015. The role of critical zone observatories in critical zone science. In 2015 principles and dynamics of the critical zone, ed. J.R. Giardino and C. Houser, 15-78. Amsterdam, The Netherlands: Elsevier.

Wymore, A., N.R. West, K. Maher, P.L. Sullivan, A. Harpold, D. Karwan, J.A. Marshall, J. Perdrial, D.M. Rempe, and L. Ma. 2017. Growing new generations of critical zone scientists. Earth Surface Processes and Landforms 42 (14): 2498-2502.

$\mathrm{Xu}$, X., M. Chen, G. Yang, and J. Zhang. 2020. Wetland ecosystem services research: A critical review. Global Ecology and Conservation 22: $\mathrm{e} 01027$.

Yang, R.-M. 2019. Interacting effects of plant invasion, climate, and soils on soil organic carbon storage in coastal wetlands. Journal of Geophysical Research Biogeosciences 124 (8): 2554-2564.

Yang, H.F., S.L. Yang, K.H. Xu, J.D. Milliman, H. Wang, Z. Yang, Z. Chen, and C.Y. Zhang. 2018a. Human impacts on sediment in the Yangtze river: A review and new perspectives. Global and Planetary Change 162: 8-17.

Yang, W., Y. Jin, T. Sun, Z. Yang, and Y. Yi. 2018b. Trade-offs among ecosystem services in coastal wetlands under the effects of reclamation activities. Ecological Indicators 92: 354-366.

Ye, Z., J. Chen, L. Gao, Z. Liang, S. Li, R. Li, G. Jin, Y. Shimuzu, S. Onodera, M. Saito, and G. Gopalakrishnan. 2020. 210Pb dating to investigate the historical variations and identification of different sources of heavy metal pollution in sediments of the Pearl River estuary, southern China. Marine Pollution Bulletin 150: 110670.

Yu, M., E. Rivera-Ocasio, T. Heartsill-Scalley, D. Davilla-Casanova, N. Rios-Lopez, and Q. Gao. 2019. Landscape-level consequences of rising sea-level on coastal wetlands: Saltwater intrusion drives displacement and mortality in the twenty-first century. Wetlands 39 (6): $1343-1355$.

Zhang, Y., Z. Zhang, H. He, Y. Chen, S. Jiang, and H. Ren. 2017. Processes of small-scale tidal flat accretion and salt marsh changes on the plain coast of Hangsu Province, China. Acta Oceanologica Sinica 36 (4): 80-86.

Zhou, Q., C. Tu, C. Fu, Y. Li, H. Zhang, K. Xiong, X. Zhao, L. Li, J.J. Waniek, and Y. Luo. 2020. Characteristics and distribution of microplastics in the coastal mangrove sediments of China. Science of the Total Environment 703: 132807.

Zhu, C., L. Guo, D. van Maren, B. Tian, X. Wang, Q. He, and Z.B. Wang. 2019. Decadal morphological evolution of the mouth zone of the Yangtze estuary in response to human interventions. Earth Surface Processes and Landforms 44 (12): 2319-2332. 